\title{
In-Situ Measurements of Mechanical Properties Using Novel Automated Ball Indentation System
}

\begin{abstract}
REFERENCE: Haggag, F. M., "In-Situ Measurements of Mechanical Properties Using Novel Automated Ball Indentation System," Small Specimen Test Techniques Applied to Nuclear Reactor Vessel Thermal Annealing and Plant Life Extension, ASTM STP 1204, W. R. Corwin F. M. Haggag, and W. L. Server, Eds., American Society for Testing and Materials, Philadelphia, 1993, pp. 27-44.
\end{abstract}

\begin{abstract}
Determination of the integrity of any metallic structure is required either to ensure that failure will not occur during the service life of the components (particularly following any weld repair) or to evaluate the lifetime extension of the structure. A portable/in-situ stress-strain microprobe system was developed to evaluate nondestructively in situ the integrity of metallic components [including base metal, welds, and heat-affected zones (HAZs)] The microprobe system utilizes an innovative automated ball indentation (ABI) technique to determine several key mechanical properties (yield strength, true-stress/true-plastic-strain curve, strain-hardening exponent, Lüders strain, elastic modulus, and an estimate of the local fracture toughness). This paper presents ABI test results from several metallic samples. The microprobe system was used successfully to nondestructively test in-situ a circumferentially welded Type 347 stainless steel pipe. Four V-blocks were used to mount the testing head of the microprobe system, allowing a $360^{\circ}$ inspection of property gradients in the weld and its HAZ.
\end{abstract}

KEYWORDS: in-situ testing, structural integrity, automated ball indentation, spherical indenter, cyclic loading, partial unloading, field apparatus, microprobe, welds, heat-affected zone, yield strength, flow properties, pipes, nuclear pressure vessel steels, nondestructive testing

The ABI test is based on strain-controlled multiple indentations (at the same penetration location) of a polished surface by a spherical indenter ( 0.25 to $1.57-\mathrm{mm}$ diameter). The microprobe system and test methods [1] are based on well demonstrated and accepted physical and mathematical relationships which govern metal behavior under multiaxial indentation loading. A summary of the ABI test technique is presented here, and more details are given elsewhere [1-14]. The microprobe system currently utilizes an electromechanically driven indenter, high-resolution penetration transducer and load cell, a personal computer (PC), a 16-bit data acquisition/control unit, and copyrighted ABI software. Automation of the test, where a 486 $\mathrm{PC}$ and a test controller were used in innovative ways to control the test (including a real-time graphic and digital display of load-depth test data) as well as to analyze test data (including tabulated summary and macro-generated plots), make it simple, rapid (less than 10 min for a complete ABI test), accurate, economical, and highly reproducible. Results of ABI tests (at several strain rates) on various base metals, welds, and HAZs at different metallurgical conditions are presented and discussed in this paper.

${ }^{1}$ Advanced Technology Corporation. 115 Clemson Drive, Oak Ridge, TN 37830-7665. 


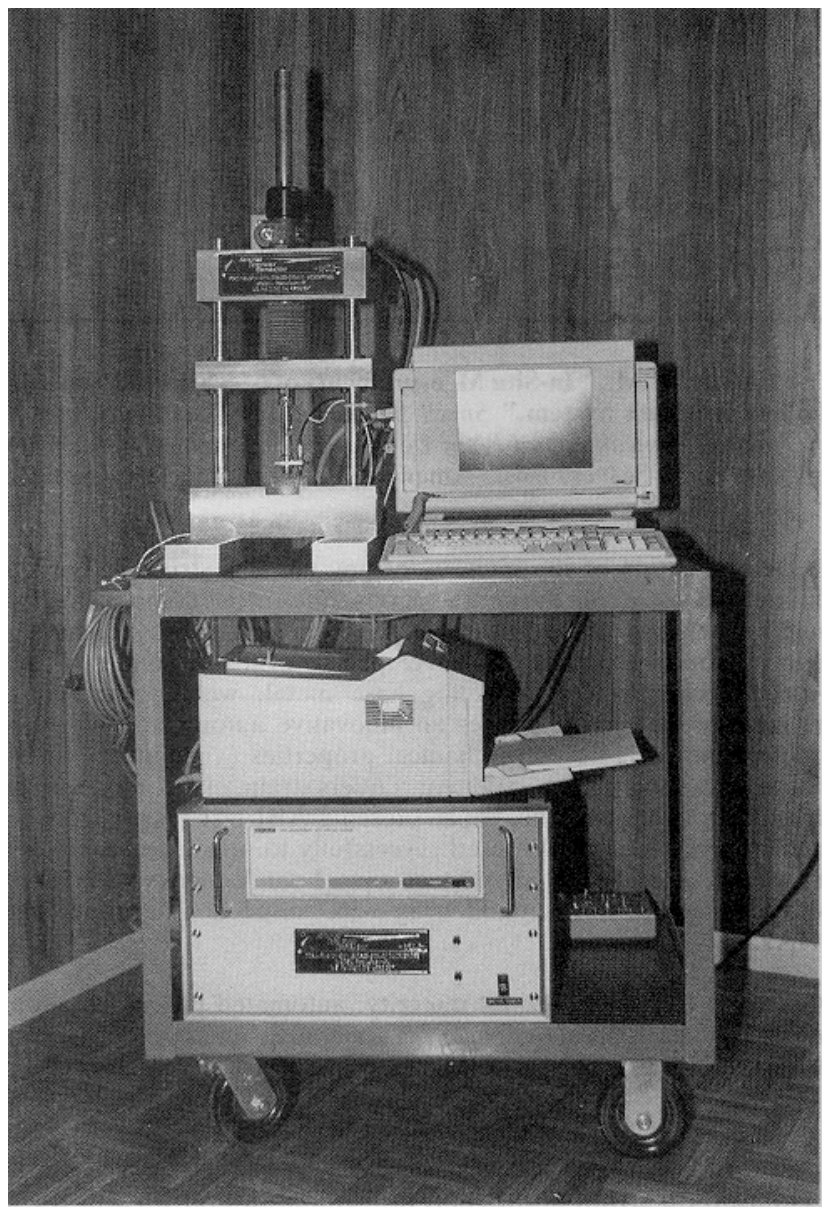

Fig. 1-The portable/in-situ stress-strain microprobe system configured for laboratory benchtop testing (the testing head has a specimen support platen).

Excellent agreement was obtained between ABI-derived data and those from conventional ASTM methods. All ABI tests were performed using a commercially available portable/in-situ stress-strain microprobe system ${ }^{2}$, the mechanics of which are described elsewhere [1].

A bench-top configuration of the microprobe (Figs. 1 and 2) was used to test laboratory base metal and weld specimens (Figs. 2 and 3) and resistance spot welds and their HAZs in 1020 carbon steel and 2219 aluminum sheets. A Charpy V-notch (CVN) block is shown underneath the ball indenter in Fig. 2. Gradients in the yield strength and flow properties and correlations to the material microstructure in the weld and HAZ areas are discussed in Ref 7. A 347 stainless steel (SS) flat specimen was also tested and the ABI results compared to its material certification. The in-situ configuration (Fig. 4) was used successfully to test a 114-mm outer diameter 347 SS pipe containing a circumferential weld (308 SS).

\footnotetext{
${ }^{2}$ Portable/ln-Situ Stress-Strain Microprobe System, Model PortaFlow-P1, U.S. Patent No. 4,852,397, Advanced Technology Corporation, 115 Clemson Drive, Oak Ridge, TN 37830-7665.
} 


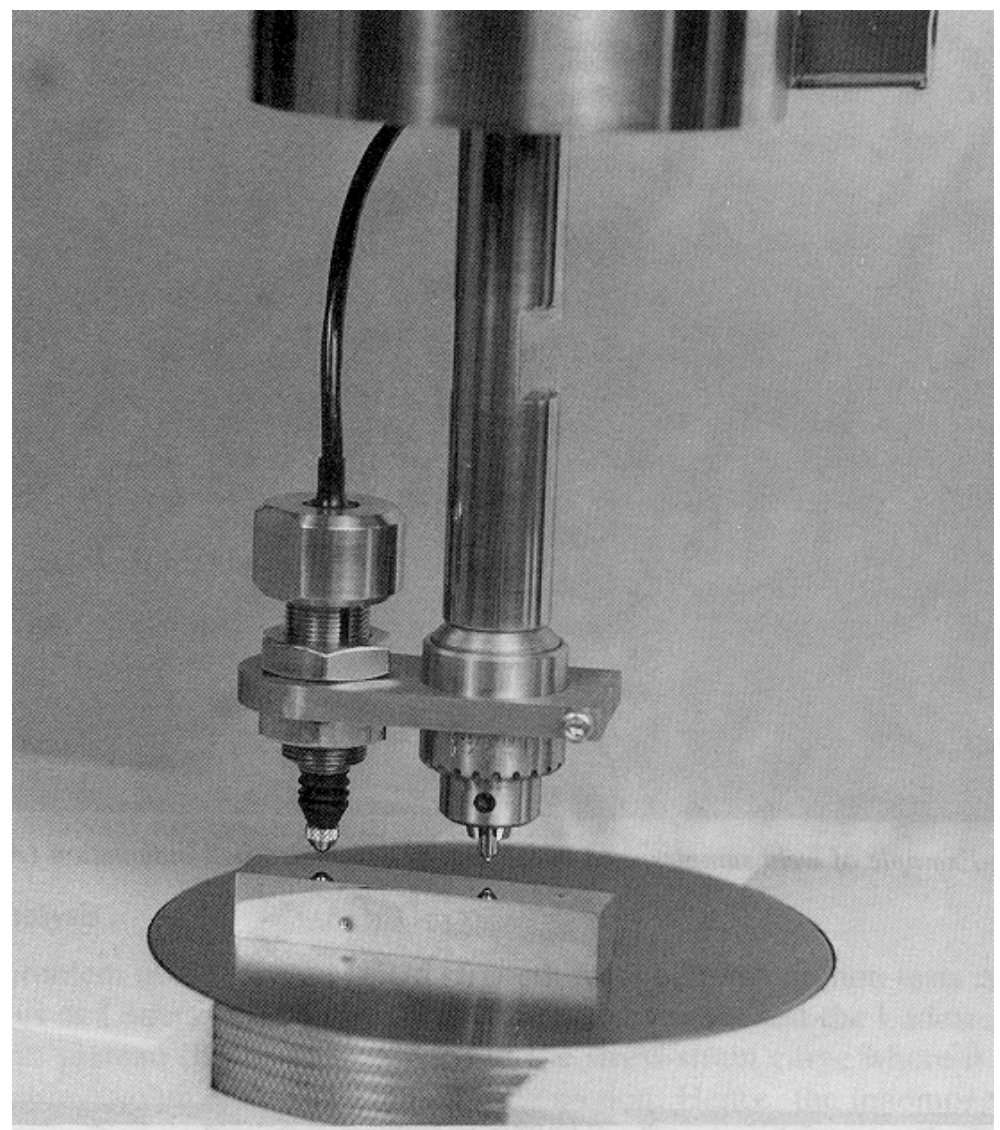

FIG. 2-Details of the ball and the LVDT of the microprobe system (a Charpy V-notch block is shown underneath the indenter.

\section{Portable/ln-Situ Stress-Strain Microprobe System and ABI Testing}

Figures 1 and 4 show the different components of the microprobe system used in this work. These include: (1) a compact testing head (Fig. 1 is the bench-top configuration with a support platen for laboratory specimen testing, while Fig. 4 shows the in-situ configuration where the testing head is mounted on a stainless steel pipe), (2) a small electronics cabinet which contains the data acquisition/control unit, other boards for signal conditioning and control, and the driver of the electric servo motor, and (3) a portable 486 personal computer. Other testing head mounts such as magnetic holders (either permanent or electric) can be used when appropriate.

The ABI test is based on multiple indentation cycles (at the same penetration location) on a polished metallic surface by a spherical indenter. Each cycle consists of indentation, unload, and reload sequences. Values of indentation penetration speed (strain rate), data acquisition rate, indentation target delta displacement (penetration depth for each cycle), unload target delta load, indentation maximum (final) load, and indentation maximum (final) displacement (penetration depth) are input before the test starts. The computer program checks all test values against limits to detect operator error. Once the test is started, operation is automatic until either maximum load 


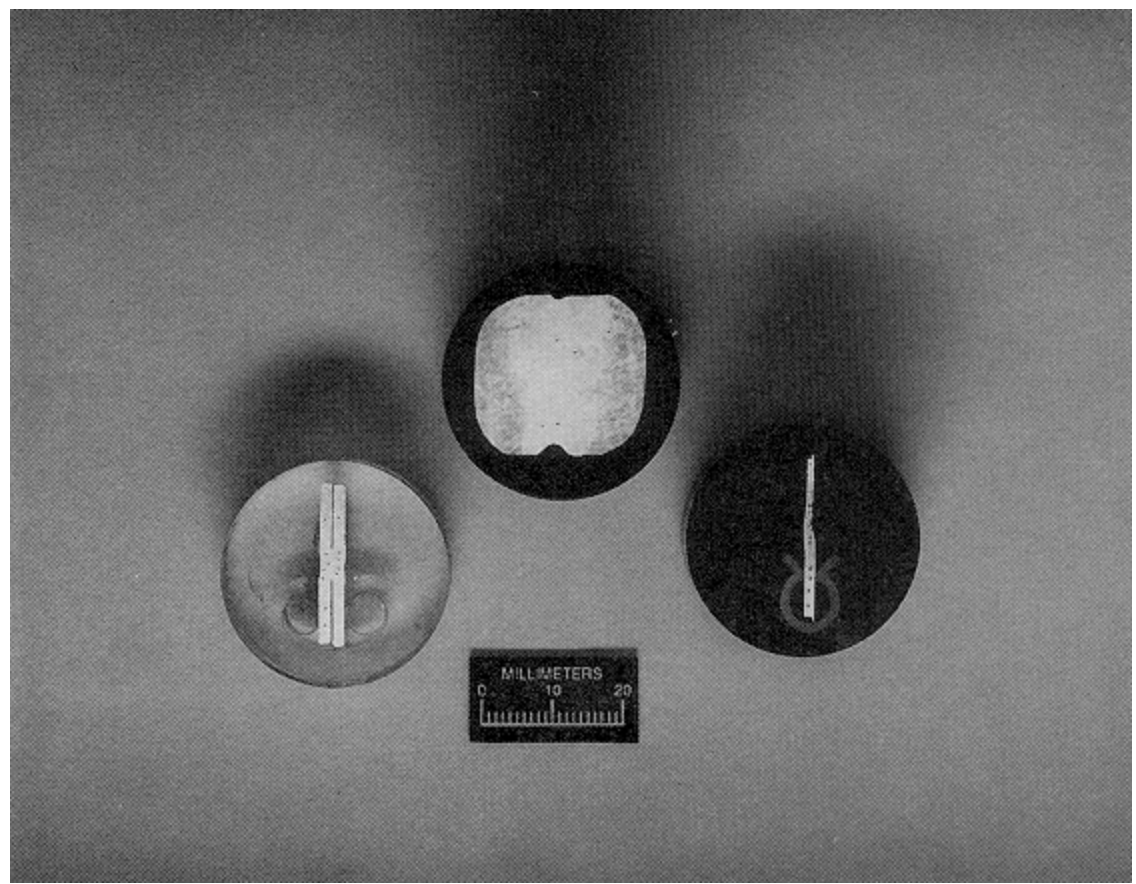

FIG. 3--Example of weld samples used in laboratory automated ball indentation (ABI) tests.

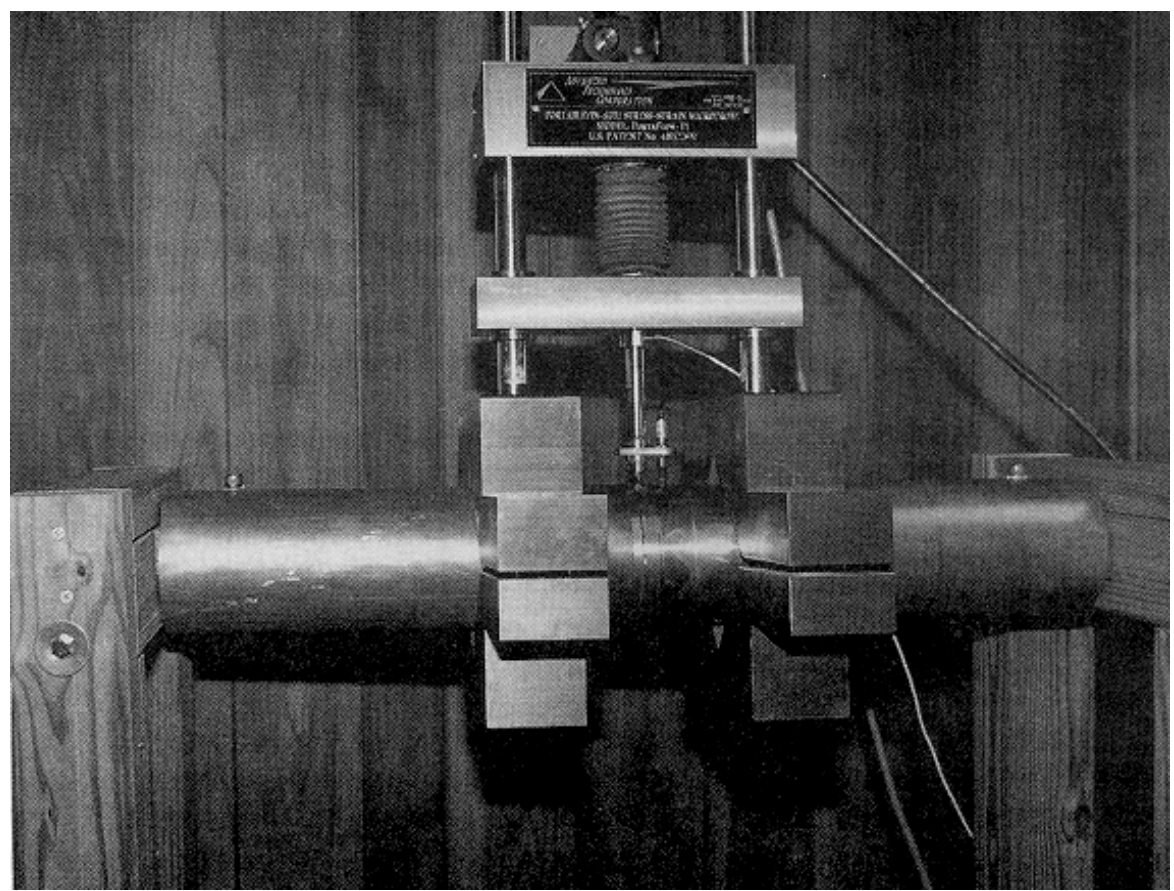

FIG. 4--The testing head of the microprobe system is mounted on a circumferentially welded 347 SS pipe (114 mm diameter) using four $900 \mathrm{~V}$-blocks. 
or maximum displacement is reached, but the operator can abort the test at any time if system malfunction is detected. Current test values for indentation load and depth are displayed digitally on the computer monitor in engineering units as well as in real-time graphics (penetration depth as $\mathrm{X}$-axis versus indentation load as $\mathrm{Y}$-axis) so the operator can monitor the test progress. The $\mathrm{ABI}$ test data are saved in memory during the test and then stored on the computer hard disc following test completion and full material sample unloading. The applied loads and associated displacements (depth of penetration of the indenter into the specimen) are measured using a load cell and a spring-loaded linear variable differential transducer (LVDT). The test setup of the current work used tungsten carbide ball indenters varying in size from 0.25 to $1.57-\mathrm{mm}$ diameter. Appropriate capacity load cells were used for the selected indenter size. Details of the ball indenter and the LVDT are shown in Fig. 2. The load-displacement data from each unloading sequence are fitted with a first degree polynomial and the fit extrapolated to obtain the displacement corresponding to zero load. These displacements and the maximum cycle load and displacement values from each indentation sequence are used to determine the yield strength, produce the ABI-derived true-stress/true-plastic-strain curve, and to estimate fracture toughness. The ABI analyses are based primarily on elasticity and plasticity theories and some empirical correlations as described in Refs I through 14. The primary equations used in these analyses are given in the next section.

\section{ABI Data Analysis}

The main problem in determining yield strength from ball indentation tests is due to the inhomogeneous or Lüders strain behavior. In a uniaxial tension test the Lüders strain is the inhomogeneous plateau (horizontal portion) of the stress-strain curve where it is confined mostly to a defined volume of the specimen gage section. Hence, the inhomogeneous (Lüders) and homogeneous (work hardening) behaviors in a tension test are well defined and separated from each other. In contrast, in an ABI test the material has less constraint at the surface around the indentation. With increasing indentation loads, an increasing volume of material is forced to flow under multiaxial compression caused by the indenter, and more material pileup and Lüders strain occur around the indentation. Thus, in an ABI test both inhomogeneous and homogeneous material behavior occur simultaneously during the entire test. Consequently, an accurate determination of yield strength should be based on the entire load-displacement curve of the ABI test as explained later. It should be emphasized here that, e.g., for an ABI test consisting of eight cycles, there will be eight yielding processes of new material each time the indenter has penetrated deeper into the test material, as well as eight processes of work hardening of both old and new material. Hence, the yield strength analysis in ABI testing should account for this simultaneous occurrence of yielding and strain hardening of test material under ABI multiaxial compression. Schematics of the ABI load-displacement plot and the profile of indentation (exaggerated to show material pileup) are shown in Figs. 5 and 6, respectively. The ABI load-displacement curve will not exhibit any Lüders plateau (e.g., as the case in uniaxial tensile tests of carbon steel materials).

\section{Flow Properties}

The homogeneous plastic flow portion of the true-stress $\left(\sigma_{\mathrm{t}}\right) /$ true-plastic-strain $\left(\varepsilon_{p}\right)$ curve can be represented by the familiar power law equation

$$
\sigma_{t}=K \varepsilon_{p}^{n}
$$




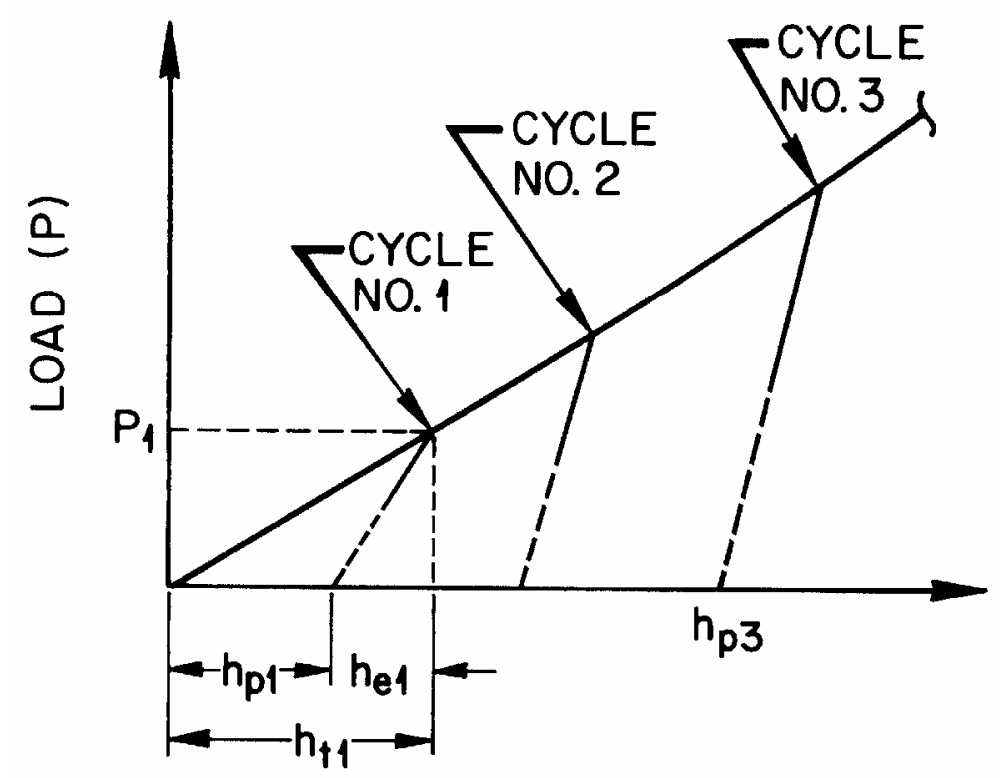

\section{DISPLACEMENT $(h)$}

FIG. 5--Schematic representation of the relationship between indentation load and penetration depth of the ball indenter as observed by increased cyclic loading. Elastic unloading slopes are not parallel because of increased spherical deformation volume as the load is increased.

where

$n=$ strain-hardening exponent, and

$K=$ strength coefficient.

It should be noted that this representation is not a necessary requirement for determining the indentation-derived $\sigma_{t}-\varepsilon_{p}$ data as will be shown later (Eqs 2 and 3), but it can be used to determine the strain-hardening exponent over the $\varepsilon_{p}$ range of interest. Furthermore, a single power curve may not fit the entire $\sigma_{t}-\varepsilon_{p}$ curve as noted in ASTM Test Method for Tensile Strain-Hardening Exponent ( $n$-Values) of Metallic Sheet Materials (E 646-78).

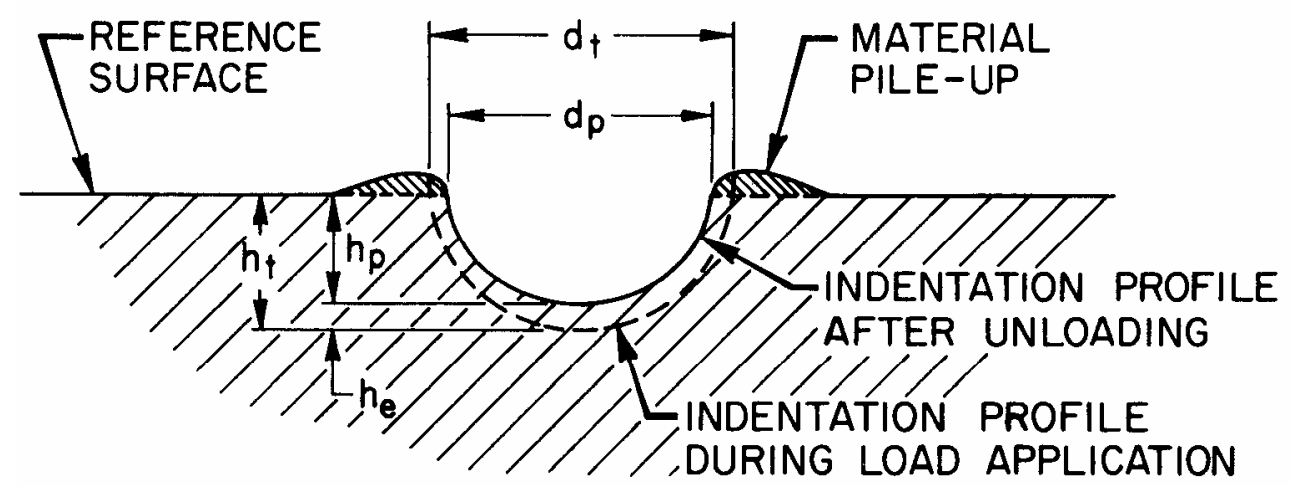

FIG. 6-Illustration of ball indentation geometries before and after load application (the material pileup is exaggerated). 
The computer program is used to solve the following equations and to thereby determine the flow curve from the ABI data.

$$
\begin{gathered}
\varepsilon_{p}=0.2 d_{p} / D \\
\sigma_{t}=4 P / \pi d_{p}^{2} \delta
\end{gathered}
$$

where

$$
\begin{gathered}
d_{p}=\left\{0.5 C D\left[h_{p}^{2}+\left(d_{p} / 2\right)^{2}\right] /\left[h_{p}^{2}+\left(d_{p} / 2\right)^{2}-h_{p} D\right]\right\}^{1 / 3} \\
C=5.47 P\left(1 / E_{1}+1 / E_{2}\right) \\
\delta=\left\{\begin{array}{rr}
1.12 & \Phi \leq 1 \\
1.12+\tau \ln \Phi & 1<\Phi \leq 27 \\
\delta_{\max } & \Phi>27
\end{array} \mid\right. \\
\Phi=\varepsilon_{p} E_{2} / 0.43 \sigma_{t} \\
\delta_{\max }=2.87 \alpha_{m} \\
\tau=\left(\delta_{\max }-1.12\right) / \ln (27)
\end{gathered}
$$

In the above equations, $\sigma_{\mathrm{t}}$, is the true stress, $\varepsilon_{\mathrm{p}}$ is the true-plastic-strain, $d_{p}$ is the plastic indentation diameter, $D$ is the diameter of the ball indenter, $\mathrm{P}$ is the applied indentation load, $h_{p}$ is the plastic indentation depth, $\mathrm{E}_{1}$, is the elastic modulus of the indenter, $\mathrm{E}_{2}$ is the elastic modulus of the test material, $\delta$ is a parameter whose value depends on the stage of development of the plastic zone beneath the indenter, $\alpha_{\mathrm{m}}$ is a parameter proportional to the strain rate sensitivity of the test material or specimen (e.g., for low strain-rate-sensitive materials $\alpha_{\mathrm{m}}=1.0$ ), and "ln" is the natural logarithm.

It can be seen that $d_{p}$ appears on both sides of Eq 4; the computer program solves this equation by iteration. Equations 3, 6, and 7 also have to be solved by iteration, since $\sigma_{t}$, depends on $\delta$, which depends on $\Phi$, which depends on $\sigma_{t}$. The computer program is used also to fit the ABI-derived $\sigma_{t}-\varepsilon_{p}$ data (calculated using Eqs 2 and 3) by linear regression analysis to the relationship of Eq 1 and to determine the strain-hardening exponent $(n)$ and the strength coefficient $(K)$. The previous equations provide means for predicting the homogeneous portion of the stress/strain curve from indentation data.

\section{Yield Strength}

For each ABI loading cycle, the total penetration depth $\left(h_{t}\right)$ is measured while the load is being applied, then converted to a total indentation diameter $\left(d_{t}\right)$ using the following equation

$$
d_{t}=2\left(h_{t} D-h_{t}^{2}\right)^{0.5}
$$

Data points from all loading cycles up to $d_{t} / D=1.0$ are fit by linear regression analysis to the following relationship

$$
P / d_{t}^{2}=A\left(d_{t} / D\right)^{m-2}
$$


where $P$ is the applied indentation load, $m$ is Meyer's coefficient, and $A$ is a test material (or specimen) parameter obtained from the regression analysis of test data of $d_{t} / D$ versus $P / d_{t}^{2}$. The test material parameter (A) is then used to calculate the yield strength $\left(\sigma_{\mathrm{y}}\right)$ of the material using the following equation

$$
\sigma_{y}=\mathrm{B}_{m} A
$$

where $\mathrm{B}_{m}$ is a material-type constant (e.g., a single value of $\mathrm{B}_{m}=0.2285$ (Ref 2) is applicable to all carbon steels whether cold rolled, hot rolled, or irradiated). The value of $\mathrm{B}_{m}$ for each class or type of material is determined from regression analysis of various tensile yield-strength values (measured from specimens with different heat treatments and flow properties and machined from different orientations) and their corresponding " $A$ " values as measured from entire ABI curves (up to $d_{t} / D=1.0$ ). In Eq 12 above, the units of $A$ and $\sigma_{\mathrm{y}}$ should be the same. The ABI approach to determine yield strength eliminates the need to measure material pileup except for residual stress evaluation and thereby significantly reduces testing time and thus cost. A major reason for the success of the above $\mathrm{ABI}$ procedure for determining yield strength from $\mathrm{ABI}$ measurements is that the yield strength, strength coefficient. Lüders strain $\left(\varepsilon_{L}\right)$, and strain hardening exponent are governed by the following relationship [8]

$$
\ln \left(K / \sigma_{y}\right)=\varepsilon_{L}-n \cdot \ln \varepsilon_{L}
$$

Previous work by $\mathrm{Au}$ et al. [10] on ferritic steel was not successful in determining the yield strength of ferritic steels from instrumented ball indentation. In that work, backward extrapolation of their true-stress/true-plastic-strain curve could result in underestimating the yield strength by as much as $70 \%$ or more. The current ABI procedure for calculating the yield strength is applicable to all metallic materials whether they exhibit Lüders strain or not. However, the value of $\mathrm{B}_{m}$ will be different for each class of materials (e.g., 0.191 for SS) and should be determined experimentally. Furthermore, empirical Eq 12 might be written in the following generic form

$$
\sigma_{y}=b_{m}+B_{m} A
$$

where $\mathrm{b}_{m}$ is a class-of-material yield-strength offset-constant. The values of $\mathrm{b}_{m}$ and $\mathrm{B}_{m}$ can be determined from the linear regression analysis of plotting $\sigma_{\mathrm{y}}$ values from tensile tests versus " $A$ " values obtained from ABI tests on the same materials.

\section{Results and Discussion}

The bench-top configuration of the stress-strain microprobe was used to test laboratory specimens of A533, A537, and A508 nuclear pressure vessel steels obtained from the Electric Power Research Institute (EPRI). The ABI-measured yield strength and strain-hardening exponent were in very good agreement with those from tension test results (Ref 15) as shown in Table 1. It should be noticed that, in Ref 15 , tension test results were reported from one specimen only for each material. If more tension specimens were tested (e.g., duplicates in each of the three orientations), a statistical comparison between average ABI and average tension test results could have been made. The ABI-measured strain-hardening exponent was compared to the tensile true uniform elongation since for materials exhibiting a power-law flow curve, it can be mathematically proven that the two values should be equal (see Appendix). Several resistance spot welds made from 1020 carbon steel and 2219 aluminum sheets were also tested successfully 
HAGGAG ON MEASURING MECHANICAL PROPERTIES

TABLE 1--Comparison of ABI and uniaxial rest results on four heats of nuclear pressure vessel steels.

\begin{tabular}{|c|c|c|c|c|}
\hline \multirow{2}{*}{$\begin{array}{c}\text { Heat No. } \\
\text { And } \\
\text { Specimen No. }\end{array}$} & \multirow{2}{*}{$\begin{array}{c}\text { ABI-True Stress/ } \\
\text { True-Plastic Strain } \\
\text { Equation }\end{array}$} & \multirow[b]{2}{*}{$\begin{array}{c}\text { ABI-Yield } \\
\text { Strength, MPa }\end{array}$} & \multicolumn{2}{|c|}{ Uniaxial Tensile (Ref 15) } \\
\hline & & & Yield, MPa & Uniform Elongation, \% \\
\hline $1 \mathrm{~b} \mathrm{~K}$ & $\alpha_{\mathrm{t}}(\mathrm{MPa})=1006 \varepsilon_{p}^{0.138}$ & 428 & & \\
\hline EEB-T22 & $\alpha_{\mathrm{t}}(\mathrm{MPa})=972 \varepsilon_{p}^{0.135}$ & 426 & 445 & 13.9 \\
\hline SA 533-b & $\alpha_{\mathrm{t}}(\mathrm{MPa})=999 \varepsilon_{p}^{0.139}$ & 424 & & \\
\hline $1 b \mathrm{~L}$ & $\alpha_{\mathrm{t}}(\mathrm{MPa})=1060 \varepsilon_{p}^{0.137}$ & 451 & & \\
\hline EFB-T33 & $\alpha_{\mathrm{t}}(\mathrm{MPa})=1045 \varepsilon_{p}^{0.140}$ & 435 & 453 & 12.1 \\
\hline SA 533-B & $\alpha_{\mathrm{t}}(\mathrm{MPa})=1069 \varepsilon_{p}^{0.139}$ & 450 & & \\
\hline $5 \mathrm{~b} \mathrm{~A}$ & $\alpha_{\mathrm{t}}(\mathrm{MPa})=912 \varepsilon_{p}^{0.143}$ & 373 & & \\
\hline GCB-T69 & $\alpha_{\mathrm{t}}(\mathrm{MPa})=854 \varepsilon_{p}^{0.141}$ & 359 & 355 & 18.9 \\
\hline \multirow[t]{2}{*}{ SA $508 \mathrm{Cl} 1$} & $\alpha_{\mathrm{t}}(\mathrm{MPa})=829 \varepsilon_{p}^{0.135}$ & 362 & & \\
\hline & $\alpha_{\mathrm{t}}(\mathrm{MPa})=849 \varepsilon_{p}^{0.139}$ & 369 & & \\
\hline $7 \mathrm{~b} \mathrm{~A}$ & $\alpha_{\mathrm{t}}(\mathrm{MPa})=989 \varepsilon_{p}^{0.138}$ & 424 & & \\
\hline GBB-T54 & $\alpha_{\mathrm{t}}(\mathrm{MPa})=960 \varepsilon_{p}^{0.131}$ & 435 & 386 & 13.6 \\
\hline SA $537 \mathrm{Cl} 2$ & $\alpha_{\mathrm{t}}(\mathrm{MPa})=902 \varepsilon_{p}^{0.126}$ & 436 & & \\
\hline
\end{tabular}

(weld nugget, HAZ, and base metal) at various strain rates. The ABI results and the microstructural evaluation are given in detail in Ref 7. An example of the true-stress/true-plastic-strain curves of these spot welds is shown in Fig. 7. This figure shows that the microprobe system is capable of determining the gradients of yield strength and flow properties in very small areas. Such a capability is essential in determining the structural integrity of spot welds and in improving the welding procedures. Figure 7 shows that the weld nugget and HAZ stress-strain curves are higher than the base metal for the 1020 carbon steel (weld over-matching), while the weld nugget and HAZ stress-strain curves were lower than the aluminum base metal (weld under-matching).

\section{In-Situ ABI Testing of Structural Components}

A flat 347 stainless steel (SS) specimen obtained from an aerospace alloy (Heat No. F846) was tested prior to testing the 347 SS pipe to establish a comparison between ABI and tension test results. The ABI-measured (from one seven-cycle test) yield strength of $315.8 \mathrm{MPa}$ was in good agreement with the tensile yield strength of $317.2 \mathrm{MPa}$ (indicated on this material's test report). A total of five ABI tests were then performed on the $114 \mathrm{~mm}$ outer diameter $347 \mathrm{SS}$ pipe $(5 \mathrm{~mm}$ thick) containing a circumferential weld (308 SS). The testing head of the portable/in-situ stress-strain microprobe system was clamped on the pipe using four $90^{\circ} \mathrm{V}$-blocks as shown in Fig. 4. This mounting method allowed the head to be rotated $360^{\circ}$ and clamped rigidly for ABI testing at any location of the weld, HAZ, or the base metal. A value of $B_{m}=0.191$ (Ref 2) was used for all ABI tests on stainless steel samples and pipe materials.

The engineering ultimate strength (UTS) can be calculated from the ABI test results as follows

$$
U T S=K \cdot(n / e)^{n}
$$



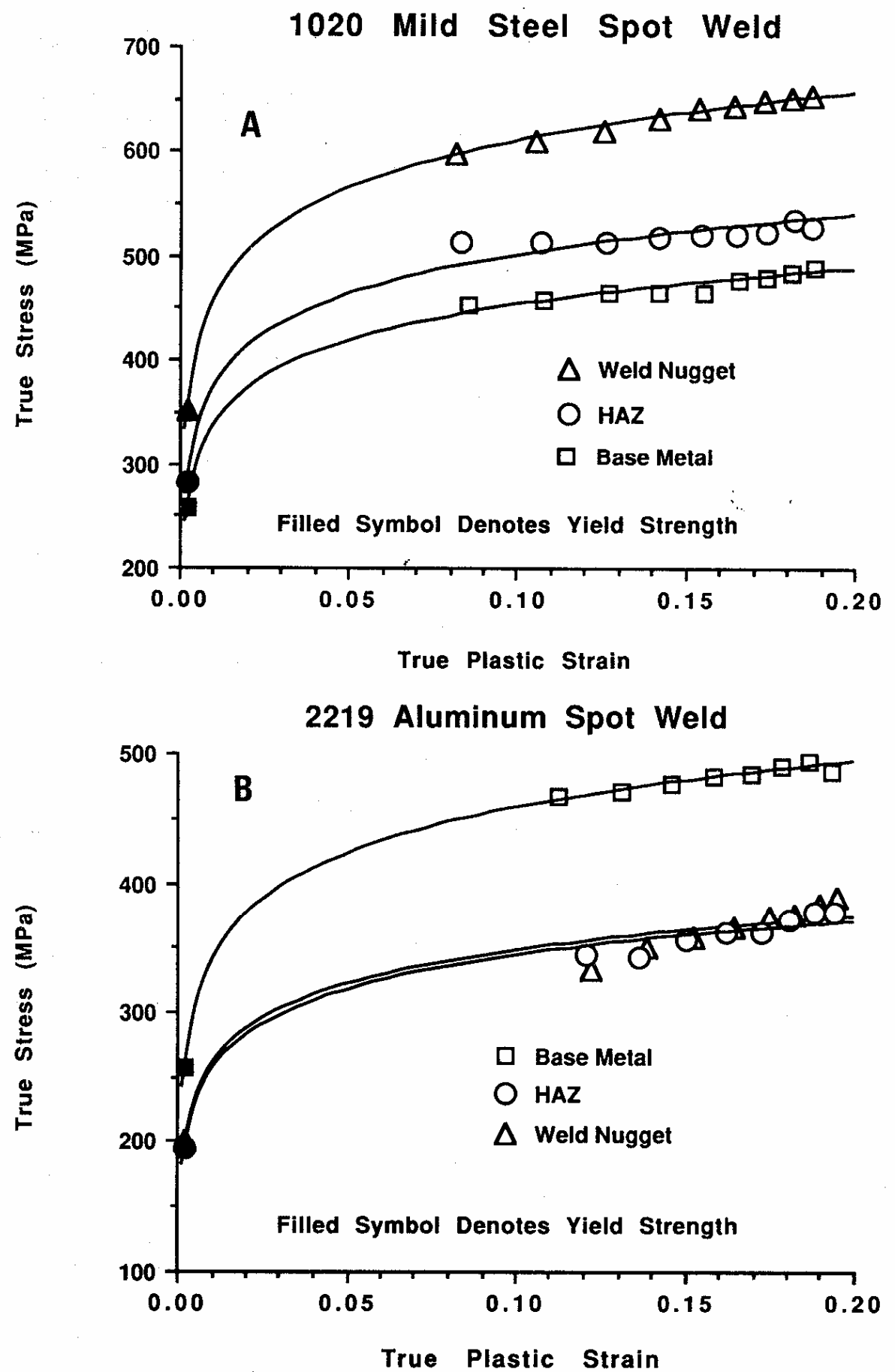

FIG. 7-Example of ABI test results on spot welds: (a) 1020 steel and (b) 2219 aluminum.

The Brinell hardness number (HB) can also be determined from the ABI test using the maximum indentation load $\left(P_{\max }\right.$ in $\left.\mathrm{kg}\right)$ and the final impression diameter $\left(\mathrm{d}_{f}\right.$ in $\left.\mathrm{mm}\right)$ and the indenter diameter (D in $\mathrm{mm}$ ) using the following equation (from ASTM Test Method for Brinell Hardness of Metallic Materials, ASTM E 10-84)

$$
H B=2 P_{\max } /\left[\pi D\left(D-\left(D^{2}-d_{f}^{2}\right)^{0.5}\right)\right]
$$


An example of the in-situ ABI test results from the welded 347 SS pipe is shown in Fig. 8, and the results are summarized in Table 2 .

The above ABI test results show that the flow properties measured by the microprobe at three circumferential weld areas are in good agreement with each other and are consistently slightly lower than those at the base metal and the HAZ test locations. The above in-situ tests also successfully demonstrate the potential applicability of the microprobe system to nondestructively test welded pipes and pressure vessels in the petroleum, fossil and nuclear power plants, etc.

\section{Fracture Toughness}

A simple technique is described [2,4] for estimating the fracture toughness by coupling the ABI-derived flow properties with a modified but empirically calibrated critical fracture strain model. This technique is currently limited to ductile fracture applications.

The critical fracture strain model for ductile fracture prediction can be expressed in the form $[16,17]$

$$
K_{J I c}=\operatorname{constant}\left(\varepsilon_{f}^{*} \cdot l_{0}^{*} \cdot E \cdot \sigma_{y}\right)^{0.5}
$$

where $K_{J I c}$ is the initiation fracture toughness calculated from $J_{\mathrm{lc}}, \varepsilon_{f}^{*}$ is the critical fracture strain, $l_{0}^{*}$, is the characteristic distance ahead of the crack tip over which the strain must exceed $\varepsilon_{f}^{*}, E$ is the elastic modulus, and $\sigma_{\mathrm{y}}$ is the yield strength. The modification [18] of this model involved: (1) the use of measured uniform strain from tension tests or the strain-hardening exponent from ABI tests instead of the critical fracture strain value required in the original model, and (2) the assumption of an empirically calibrated value for the characteristic distance, $l_{0}^{*}$, for each class of material. The ABI test technique used in this work provides an alternative method to determine the yield strength, $\sigma_{\mathrm{y}}$, and the strain-hardening exponent, $n$, (for most metals exhibiting a power law behavior one can mathematically prove that the strain-hardening exponent, $n$, is equal to the uniform ductility, $\varepsilon_{u}$ ) in a nondestructive manner, which will be more favorable over tension testing for field applications and when limited materials are available.

The determination of the critical fracture strain, $\varepsilon_{f}{ }^{*}$, requires testing of several circumferentially notched round tension specimens, each having a different value of its notch root radius. Since this approach is costly, values of the critical fracture strain, $\varepsilon_{f}^{*}$, were not determined for the materials used in this work and " $n$ " values were used instead.

The modified critical strain model can now be written as

$$
K_{J I c}=\operatorname{constant}\left(n \cdot l_{0}^{*} \cdot E \cdot \sigma_{y}\right)^{0.5}
$$

The characteristic distance, $l_{0}^{*}$, for ductile fracture is usually a multiple of the interparticle spacing and should be regarded as essentially an empirically obtained quantity. Although this dimension is presumably of relevance to the microstructural aspects of fracture initiation, it is plausibly related to the yield strength, strain-hardening exponent (a measure of work hardening), and the strength coefficient of the test material. However, more research is needed to better quantify and define this dimension in order to be able to use this method of estimating fracture toughness for applications where this characteristic distance is expected to change (e.g., due to radiation embrittlement).

Since the critical fracture strain, , values were not determined experimentally, strain-hardening values were used in the calculations [2,4]. Although such a substitution has no theoretical basis, it was considered reasonable since the critical fracture strain is often proportional to the uniform 

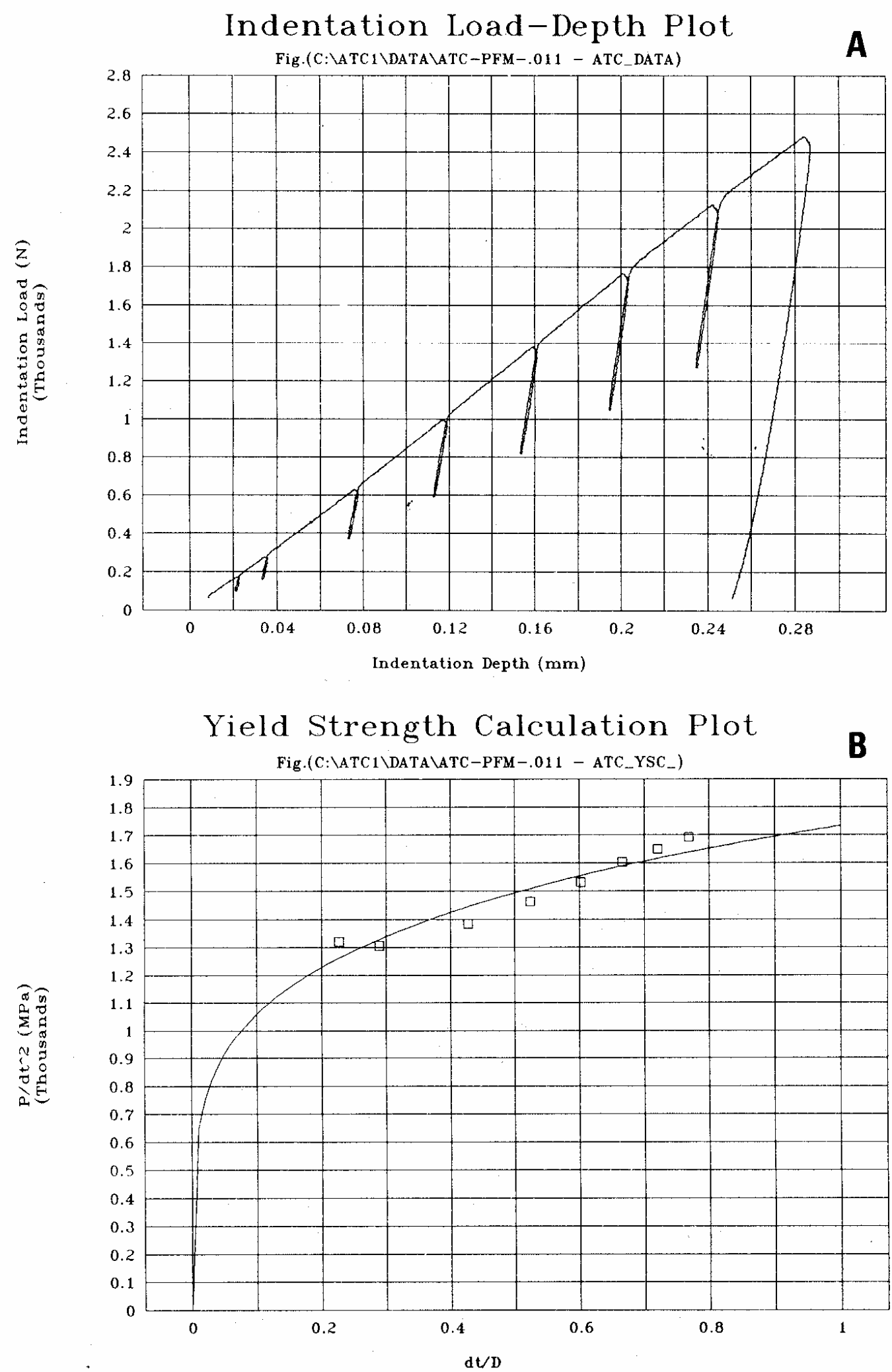

FIG. 8-In-situ ABI test results of the HAZ in welded 347 stainless steel pipe using a 1.57-mm-diameter tungsten carbide ball indenter: (a) indentation load-depth plot, (b) yield strength calculation plot, (c) true-stress/true-plastic-strain data and curve fitting, (d) log true-stress/log true-plastic-strain (slope is equal to strain-hardening exponent, n). 

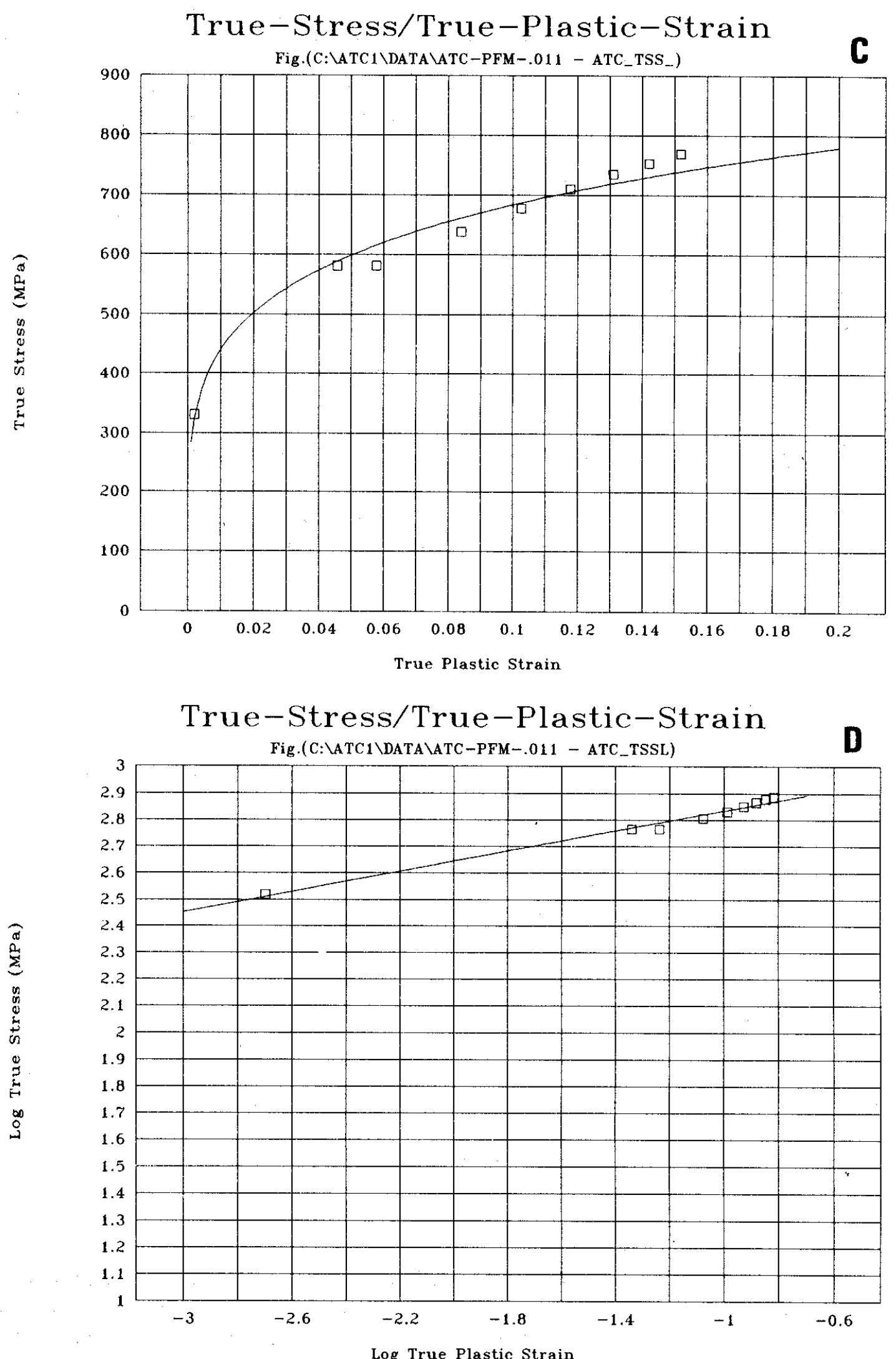

FIG. 8-Continued 
TABLE 2-Summary of in-situ ABI test results from welded 347 SS pipe.

\begin{tabular}{lcccc}
\hline & $\begin{array}{c}\text { ABI-True Stress/ } \\
\text { True-Plastic Strain } \\
\text { Equation }\end{array}$ & $\begin{array}{c}\text { ABI-Yield } \\
\text { Strength, MPa }\end{array}$ & $\begin{array}{c}\text { Ultimate } \\
\text { Strength, MPa }\end{array}$ & $\begin{array}{c}\text { Brinell } \\
\text { Hardness }\end{array}$ \\
\hline Weld Metal (308 SS) & & & & \\
Test No. 1 & $\sigma_{\mathrm{t}}(\mathrm{MPa})=990 \varepsilon_{\mathrm{p}}^{0.198}$ & 283 & 589 & 169 \\
Test No. 2 & $\sigma_{\mathrm{t}}(\mathrm{MPa})=920 \varepsilon_{\mathrm{p}}^{0.190}$ & 283 & 555 & 164 \\
$\quad$ Test No. 3 & $\sigma_{\mathrm{t}}(\mathrm{MPa})=971 \varepsilon_{\mathrm{p}}^{0.190}$ & 300 & 586 & 172 \\
HAZ & $\sigma_{\mathrm{t}}(\mathrm{MPa})=1060 \varepsilon_{\mathrm{p}}^{0.191}$ & 331 & 638 & 186 \\
$\quad \begin{array}{l}\text { Test No. 4 } \\
\text { Base Metal (347 SS) }\end{array}$ & $\sigma_{\mathrm{t}}(\mathrm{MPa})=1097 \varepsilon_{\mathrm{p}}^{0.197}$ & 325 & 654 & 188 \\
$\quad$ Test No. 5 & & & & \\
\hline
\end{tabular}

strain for a smooth tensile specimen [19]. The proportionality constant would thus be included in the constant coefficient of Eq 18. The value of 3.00 for this constant is good for steels whether in the irradiated [18] or deformed [20] condition; however, this value might be different for other classes of materials such as titanium or aluminum alloys, and further research is needed to determine the appropriate value of this constant via empirical calibration.

For estimating fracture toughness in certain applications, ABI testing can augment or replace tension testing because it is simple, fast, nondestructive, and can be performed in-situ, using the field microprobe apparatus, to evaluate deformed components and aged and embrittled structural components (provided that characteristic distance values are available from open literature). Furthermore, the ABI technique uses a very small volume of test material. Hence, it could prove valuable in new alloy development and when limited amounts of material are available. Other applications might include weld characterization and qualification, testing of near-net-shape manufactured components, and residual life assessment.

A new empirical model, used successfully in this work for estimating the fracture toughness in A508 Class 4 forging, is described by the following equation

$$
K_{J I c}=\operatorname{constant}\left(K \cdot d \cdot n \cdot \sigma_{y}\right)^{0.5}
$$

where $d$ is the grain size of the test material, $K$ is the strength proportionality constant, $n$ is the strain-hardening exponent, and $\sigma_{\mathrm{y}}$ is the yield strength. The remaining parameter needs to be estimated and verified by correlations with more extensive database. This model eliminates the need for the characteristic distance and uses three parameters measured from ABI tests (namely, $\sigma_{\mathrm{y}}, \mathrm{K}$, and $n$ ). Furthermore, the grain size could be determined, nondestructively, in the field for structural components using portable metallography equipment. However, more fracture toughness and ABI measurements are needed to quantify the applicability of this model to many heats of materials.

A total of twelve ABI tests were conducted on a 12-mm-thick slice of A508 Class 4 forging obtained from Westinghouse Plant Apparatus Division, Pa. The fracture toughness of this material measured from 25.4-mm-thick specimen tested at room temperature (Specimen I.D.: BW281, composition F. 2004) was $204 \mathrm{MPa} \sqrt{m}$. Using the results from the twelve ABI tests and the model of Eq 18 and using an assumed characteristic distance $\left(l_{0}^{*}\right)$ of $350 \mu \mathrm{m}(0.01378$ in.) - as reported earlier for A533 Grade B Class 1 steel by Ritchie et al. [17] - the average estimated fracture toughness was $207 \mathrm{MPa} \sqrt{m}$ with a standard deviation of $4 \mathrm{MPa} \sqrt{m}$. 
Another twelve ABI tests were conducted on the side surfaces far from the fracture planes of four 25.4-mm-thick compact specimens (ITCS) of the same A508 Class 4 forging material used above. These specimens were tested previously according to ASTM Test Method for $J_{\text {lc }}$, A Measure of Fracture Toughness (E 813-89), and their fracture toughness values for Specimens 1 through 4 were 292, 249, 196, and $180 \mathrm{MPa} \sqrt{m}$, respectively. The results are summarized in Table 3, where a value of $350 \mu \mathrm{m}$ was assumed for the characteristic distance for the model of Eq 18. For estimating fracture toughness from $\mathrm{ABI}$ test results using the model of Eq 19, the constant was taken as 97 and measured grain size values of 50,41,52, and $39 \mu \mathrm{m}$ were used for Specimens 1 through 4, respectively. Table 3 shows a fair agreement between 13 each ABI-estimated fracture toughness values using the models of Eqs 18 and 19 and those measured from four $J_{\text {lc }}$ tests. These results also demonstrate the need for further development of the proposed models.

In summary, the results of the ABI tests on several metallic samples and structural components (including welds and HAZs) are reproducible and show excellent agreement with the results from standard tension tests. Furthermore, automation of the ball indentation test makes it accurate, simple, strain rate controlled, fast (less than 10 min per test), and economical (cheaper than a destructive tension test, particularly for irradiated materials) for both field and laboratory applications. It should be emphasized here that results from ABI tests conducted under multiaxial compression loading may not correlate with results from uniaxial tension tests conducted on materials that exhibit different behavior under tensile or compression loading, such as those fabricated from powder compacts. Some fracture toughness values estimated from ABI data are in good agreement with those measured using the unloading compliance technique. For others, better correlations need to be developed and verified.

TABLE 3-Comparison of estimated (using ABI data) and measured fracture toughness values for A508 class 4 forging tested at room temperature.

\begin{tabular}{|c|c|c|c|c|c|}
\hline \multirow{2}{*}{$\begin{array}{l}\text { Specimen/ } \\
\text { ABI Test No. }\end{array}$} & \multirow{2}{*}{$\begin{array}{l}\text { ABI Yield } \\
\text { Strength, } \\
\text { MPa }\end{array}$} & \multirow{2}{*}{$\begin{array}{c}\text { ABI Flow Properties } \\
\text { Equation, } \mathrm{MPa}\end{array}$} & \multicolumn{2}{|c|}{$\begin{array}{l}\text { ABI Estimated } \\
\text { Fracture } \\
\text { Toughness, } \\
\text { MPa } \sqrt{m}\end{array}$} & \multirow{2}{*}{$\begin{array}{l}\text { Measured Fracture } \\
\text { Toughness, MPa } \sqrt{m} \\
\text { (From } \mathrm{J}_{\mathrm{Ic}}\end{array}$} \\
\hline & & & Eq 18 & $\mathrm{Eq} 19$ & \\
\hline \multicolumn{6}{|l|}{ Specimen No 1} \\
\hline Test No. 13 & 560 & $\sigma_{\mathrm{t}}=1275 \varepsilon_{\mathrm{p}}^{0.134}$ & 220 & 212 & \\
\hline Test No. 14 & 547 & $\sigma_{\mathrm{t}}=1276 \varepsilon_{\mathrm{p}}^{0.138}$ & 221 & 213 & 292 \\
\hline Test No. 19 & 538 & $\sigma_{\mathrm{t}}=1330 \varepsilon_{\mathrm{p}}^{0.141}$ & 221 & 218 & \\
\hline \multicolumn{6}{|l|}{ Specimen No. 2} \\
\hline Test No. 22 & 578 & $\sigma_{\mathrm{t}}=1319 \varepsilon_{\mathrm{p}}^{0.134}$ & 225 & 199 & \\
\hline Test No. 23 & 565 & $\sigma_{\mathrm{t}}=1371 \varepsilon_{\mathrm{p}}^{0.140}$ & 227 & 204 & 249 \\
\hline Test No. 21 & 555 & $\sigma_{\mathrm{t}}=1330 \varepsilon_{\mathrm{p}}^{0.135}$ & 220 & 196 & \\
\hline \multicolumn{6}{|l|}{ Specimen No. 3} \\
\hline Test No. 27 & 561 & $\sigma_{\mathrm{t}}=1350 \varepsilon_{\mathrm{p}}^{0.140}$ & 226 & 227 & \\
\hline Test No. 28 & 567 & $\sigma_{\mathrm{t}}=1421 \varepsilon_{\mathrm{p}}^{0.143}$ & 229 & 237 & 196 \\
\hline Test No. 25 & 576 & $\sigma_{\mathrm{t}}=1198 \varepsilon_{\mathrm{p}}^{0.122}$ & 214 & 203 & \\
\hline Test No. 24 & 585 & $\sigma_{\mathrm{t}}=1182 \varepsilon_{\mathrm{p}}^{0.124}$ & 217 & 204 & \\
\hline \multicolumn{6}{|l|}{ Specimen No. 4} \\
\hline Test No. 16 & 566 & $\sigma_{\mathrm{t}}=1175 \varepsilon_{\mathrm{p}}^{0.124}$ & 214 & 174 & \\
\hline Test No. 29 & 574 & $\sigma_{\mathrm{t}}=1248 \varepsilon_{\mathrm{p}}^{0.127}$ & 217 & 182 & 180 \\
\hline
\end{tabular}


A larger database is needed to quantify the accuracy of estimated fracture toughness values. Furthermore, the microprobe capabilities for nondestructive in-situ testing of structural components (base metal, weld, HAZ) have been demonstrated. Such capabilities will be very useful in testing nuclear pressure vessels during their design service life and before and after their thermal annealing. Moreover, the use of the microprobe for in-situ testing could eliminate both cutting of boat samples from nuclear pressure vessel and machining of irradiated specimens. For nuclear pressure vessels with a thin layer of inside stainless steel cladding, local areas (approximately $3 \mathrm{~mm}$ in diameter) of the cladding can be ABI tested and then removed (drilled) such that the thick ferritic steel material underneath can be ABI tested successfully.

\section{Conclusions}

1. The ABI technique was very successful in accurately determining the yield strength and measuring the flow properties of welds in several metallic materials (e.g., A533B-1, A508, A537, 1020, 347 SS, 308 SS, and 2219 aluminum).

2. The gradients in mechanical properties of weld metals and their HAZs were successfully determined from ABI tests conducted on both laboratory specimens as well as on structural components (114 mm outer diameter 347 stainless steel pipe containing a circumferential weld).

3. The ABI results from tests conducted on curved structures were in excellent agreement with those from tests conducted on similar flat specimens.

4. In-situ (field) ABI tests on pipes were proven to be nondestructive, accurate, reproducible, and fast (less than 10 min per test). Hence, the microprobe system could be used for life-time extension evaluation of nuclear power plant components (e.g., pressure vessels and their supports). One prime example could be to determine the degree of ductility recovery of aged nuclear pressure vessels following their thermal annealing.

5. Preliminary results of fracture toughness estimation methods from ABI measurements show varying degrees of agreement with conventional data and should be investigated further.

\section{APPENDIX}

\section{Relationship between True Uniform Elongation and Strain-Hardening Exponent}

The homogeneous plastic flow portion of the true-stress $\left(\sigma_{t}\right) /$ true-plastic-strain $\left(\varepsilon_{\mathrm{p}}\right)$ curve can be represented by the familiar power law equation

$$
\sigma_{t}=K \varepsilon_{p}^{n}
$$

where

$$
\begin{aligned}
& \quad n=\text { strain-hardening exponent } \\
& K=\text { strength coefficient } \\
& \text { Load }=P \\
& \text { Cross-section area of tensile specimen }=A \\
& \text { Instantaneous specimen gage length }=l \\
& \text { Volume of specimen gage section }=V
\end{aligned}
$$

$$
\begin{gathered}
P=\sigma_{t} A \\
d P=\sigma_{t} d A+A d \sigma_{t}
\end{gathered}
$$


Since necking occurs at maximum load, $d P=0$

$$
d \sigma_{t} / \sigma_{t}=-d A / A
$$

From constancy of volume $(V=A l), d V=A d l+l d A=0$

$$
-d A / A=d l / l
$$

Since $d l / l \equiv d \varepsilon_{p}$

Combining Eqs 4, 5, and 6

$$
\sigma_{t}=d \sigma_{t} / d \varepsilon_{p}
$$

From Eqs 1 and 7

$$
K \varepsilon_{p}^{n}=K n \varepsilon_{p}^{n-1}
$$

At necking, the true-plastic strain $\left(\varepsilon_{\mathrm{p}}\right)$ equals the true uniform elongation $\left(\varepsilon_{\mathrm{u}}\right)$.

Therefore from $\mathrm{Eq} 8$

$$
n=\varepsilon_{u}
$$

Hence, the true uniform elongation is numerically equal to the strain-hardening exponent.

\section{References}

[1] Haggag, F. M.., "Field Indentation Microprobe for Structural Integrity Evaluation," U.S. Patent No. 4,852,397, 1 Aug. 1989.

[2] Haggag, F. M., Nanstad, R. K., Hutton, J. T., Thomas, D. L., and Swain, R. L., "Use of Automated Ball Indentation Testing to Measure Flow Properties and Estimate Fracture Toughness in Metallic Materials," Applications of Automation Technology to Fatigue and Fracture Testing, ASTM STP 1092, A. A. Braun, N. E. Ashbaugh, and F. M. Smith, Eds., American Society for Testing and Materials, Philadelphia, 1990, pp. 188-208.

[3] Haggag, F. M., Nanstad, R. K., and Braski, D. N., "Structural Integrity Evaluation Based on an Innovative Field Indentation Microprobe," Innovative Approaches to Irradiation Damage and Failure Analysis, D. L. Marriott, T. R. Mager, and W. H. Bamford, Eds., PVP Vol. 170, American Society of Mechanical Engineers, New York, 1989, pp. 101-107.

[4] Haggag, F. M. and Nanstad, R. K., "Estimating Fracture Toughness Using Tension or Ball Indentation Tests and a Modified Critical Strain Model," Innovative Approaches to Irradiation Damage and Failure Analysis, D. L. Marriott, T. R. Mager, and W. H. Bamford, Eds., PVP Vol. 170, American Society of Mechanical Engineers, New York, 1989, pp. 41-46.

[5] Haggag, F. M., Wong, H., Alexander, D. J., and Nanstad, R. K., "The Use of Field Indentation Microprobe in Measuring Mechanical Properties of Welds," Recent Trends in Welding Science and Technology, TWR'89, Proceedings of the 2nd International Conference on Trends in Welding Research, Gatlinburg, TN, 14-18 May, 1989, 1990, pp. 843-849.

[6] Haggag, F. M., "Application of Flow Properties Microprobe to Evaluate Gradients in Weldment Properties," International Trends in Welding Sciences and Technology, S. A. David and J. M. Vitek, Eds., ASM, Metals Park, OH, 1993, pp. 629-635.

[7] Haggag, F. M. and Bell, G. E. C., "Measurement of Yield Strength and Flow Properties in Spot Welds and Their HAZs at Various Strain Rates," International Trends in Welding Science and Technology, S. A. David and J. M. Vitek, Eds., ASM, Metals Park, OH, 1993, pp. 637-642.

[8] Haggag, F. M., "The Role of Lüders Strain in Predicting Flow Properties in Steels from an Instrumented Hardness Test," M.S. thesis, Department of Chemical and Nuclear Engineering, University of California, Santa Barbara, CA, 1980.

[9] Haggag, F. M. and Lucas, G. E., "Determination of Lüders Strains and Flow Properties in Steels from Hardness/Microhardness Tests," Metallurgical Transactions A, Vol. 14A, 1983, pp. 1607-1613. 
[10] Au, P., Lucas, G. E., Sheckherd, J. W., and Odette, G. R., "Flow Property Measurements from Instrumented Hardness Tests," Non-destructive Evaluation in the Nuclear Industry, American Society for Metals, Metals Park, OH, 1980, pp. 597-610.

[12] Tabor, D., The Hardness of Metals, Clarendon Press, Oxford, 1951.

[13] Francis, H. A., "Phenomenological Analysis of Plastic Spherical Indentations," Transactions of the ASME, July 1976, pp. 272-281.

[14] George, R. A., Dinda, S., and Kasper, A. S., "Estimating Yield Strength from Hardness Data," Metal Progress, May 1976, pp. 30-35.

[15] Server, W. L. and Oldfield, W., "Nuclear Pressure Vessel Steel Data Base," EPRI Report NP-933, Electric Power Research Institute, Palo Alto, CA, 1978.

[16] Pandey, R. K., and Banerjee, S., "Strain Induced Fracture in Low Strength Steels," Engineering Fracture Mechanics, Vol. 10, 1978, pp. 817-829.

[17]Ritchie, R. O., Server, W. L., and Waullaert, R. A., "Critical Fracture Stress and Fracture Strain Models for Prediction of Lower and Upper Shelf Toughness in Nuclear Pressure Vessel Steels," Metallurgical Transactions A, Vol. 10A, 1979, pp. 1557-1570.

[18] Haggag, F. M., Reuter, W. G., and Server, W. L., "Recovery of Fracture Toughness of Irradiated Type 347 Stainless Steel Due to Thermal Stress Relief: Metallographic and Fractographic Studies," Proceedings of the 2nd International Symposium on Environmental Degradation of Materials in Nuclear Power Systems-Water Reactors, Monterey, CA, 9-12 Sept. 1985, pp. 509-514.

[19]Pavinich, W. A., "The Effect of Neutron Fluence and Temperature on the Fracture Toughness and Tensile Properties for a Linde 80 Submerged Arc Weld," Proceedings of the 2nd International Symposium on Environmental Degradation of Materials in Nuclear Power Systems-Water Reactors, Monterey, California, 9-12 Sept. 1985, pp. 485-495.

[20] Haggag, F. M., Server, W. L., Lucas, G. E., Odette, G. R., and Sheckherd, J. W., "The Use of Miniaturized Tests to Predict Flow Properties and Estimate Fracture Toughness in Deformed Steel Plates," Journal of Testing and Evaluation, JTEVA, Vol. 1, No. 1, January 1990, pp. 62-69. 